\title{
A new electronically tunable voltage-mode active-C phase shifter using UVC and OTA
}

\author{
Norbert Herencsar ${ }^{\text {a) }}$, Jaroslav Koton, and Kamil Vrba \\ Brno University of Technology, Faculty of Electrical Engineering and \\ Communication, Department of Telecommunications, Purkynova 118, \\ 61200 Brno, Czech Republic \\ a) herencsn@feec.vutbr.cz
}

\begin{abstract}
In this paper, a new voltage-mode first-order all-pass filter is presented. The proposed filter provides both of non-inverting and inverting outputs at the same configuration. The circuit is composed of single universal voltage conveyor (UVC), operational transconductance amplifier (OTA), and capacitor. Considering the electronically tunability properties of the OTA phase responses of the proposed active-C circuit can be controlled by an external bias current. The circuit is suitable for wideband applications. All the active and passive sensitivities are low. The theoretical results are verified by PSPICE simulations using BJT implementations of UVC and OTA.
\end{abstract}

Keywords: all-pass filter, analog signal processing, OTA, phase shifter, UVC, voltage-mode

Classification: Electron devices, circuits, and systems

\section{References}

[1] A. Toker, S. Ozcan, H. Kuntman, and O. Cicekoglu, "Supplementary all-pass sections with reduced number of passive elements using a single current conveyor," Int. J. Electron., vol. 88, no. 9, pp. 969-976, 2001.

[2] J. W. Horng, "Current conveyors based allpass filters and quadrature oscillators employing grounded capacitors and resistors," Computers and Electrical Engineering, vol. 31, no. 1, pp. 81-92, 2005.

[3] M. A. Ibrahim, H. Kuntman, and O. Cicekoglu, "First-order all-pass filter canonical in the number of resistors and capacitors employing a single DDCC," Circuits, Syst., Signal Process., vol. 22, no. 5, pp. 525-536, 2003.

[4] H. P. Chen, M. T. Lin, and W. S. Yang, "Novel first-order non-inverting and inverting output of all-pass filter at the same configuration using ICCII," IEICE Trans. Electron., vol. E89-C, no. 6, pp. 865-867, 2006.

[5] H. P. Chen and M. T. Lin, "Voltage-mode first-order filter using single DDCC," Electron. World, vol. 112, no. 1844, pp. 50-51, 2006.

[6] S. Maheshwari, "High input impedance voltage-mode first-order all-pass sections," Int. J. Circuit Theory Appl., vol. 36, no. 4, pp. 511-522, 2008.

[7] B. Metin and K. Pal, "Cascadable allpass filter with a single DO-CCII and a grounded capacitor," Analog Integrated Circuits Signal Process., Article in Press, 2009, DOI 10.1007/s10470-009-9301-2.

[8] T. Dostal and J. Pospisil, "Hybrid models of 3-port immittance conver- 
tors and current and voltage conveyors," Electron. Lett., vol. 18, no. 20, pp. 887-888, 1982.

[9] M. Minarcik and K. Vrba, "Low-output and high-input impedance frequency filters using universal voltage conveyor for high-speed data communication systems," In Proc. IARIA 5th Int. Conference on Networking - ICN'06, Mauritius, pp. 155-158, 2006.

[10] K. Salama and A. Soliman, "Novel MOS-C quadrature oscillator using the differential current voltage conveyor," In Proc. 42nd Midwest Symposium on Circuits and Systems - MWSCAS'99, Las Cruces, USA, pp. 279-282, 1999.

[11] C. Acar and S. Ozoguz, "A new versatile building block: current differencing buffered amplifier suitable for analog signal processing filters," Microelectronics Journal, vol. 30, no. 2, pp. 157-160, 1999.

[12] A. Carlosena, R. Cabeza, and L. Serrano, "On the search for a universal active element," In Proc. IEEE Int. Symposium on Circuits and Systems ISCAS'94, London, UK, pp. 779-782, 1994.

[13] D. Becvar, K. Vrba, V. Zeman, and V. Musil, "Novel universal active block: a universal current conveyor," In Proc. IEEE Int. Symposium on Circuits and Systems - ISCAS'00, Geneva, Switzerland, pp. 471-474, 2000.

[14] N. Herencsar and K. Vrba, "Current conveyors-based circuits using novel transformation method," IEICE Electron. Express, vol. 4, no. 21, pp. 650-656, 2007.

[15] J. Jerabek and K. Vrba, "SIMO type low-input and high-output impedance current-mode universal filter employing three universal current conveyors," Int. J. Electron. Commun. (AEU), Article in Press, 2009. DOI: 10.1016/j.aeue.2009.03.002.

[16] M. Minarcik and K. Vrba, "Single-input six-output voltage-mode filter using universal voltage conveyors," IEICE Trans. Fundamentals, vol. E91-A, no. 8, pp. 2035-2037, 2008.

[17] J. Koton, K. Vrba, and N. Herencsar, "Tuneable filter using voltage conveyors and current active elements," Int. J. Electron., vol. 96, no. 8, pp. 787-794, 2009.

[18] N. Herencsar, K. Vrba, J. Koton, and I. Lattenberg, "The conception of differential-input buffered and transconductance amplifier (DBTA) and its application," IEICE Electron. Express, vol. 6, no. 6, pp. 329-334, 2009.

[19] N. Herencsar, J. Koton, K. Vrba, and I. Lattenberg, "New voltage-mode universal filter and sinusoidal oscillator using only single DBTA," Int. J. Electron., accepted, to be published, 2009.

[20] R. L. Geiger and E. Sanchez-Sinencio, "Active filter design using operational transconductance amplifiers: a tutorial," IEEE Circuits Devices Mag., vol. 1, no. 2, pp. 20-32, 1985.

[21] M. Siripruchyanun and W. Jaikla, "Current controlled current conveyor transconductance amplifier (CCCCTA): a building block for analog signal processing," Electrical Engineering, vol. 90, no. 6, pp. 443-453, 2008.

[22] M. T. Abuelma'atti and S. M. Al-Shahrani, "A novel low-componentcount single-element-controlled sinusoidal oscillator using the CFOA pole," Int. J. Electron., vol. 80, no. 6, pp. 747-752, 1996.

[23] T. Deliyannis, Y. Sun, and J. K. Fidler, Continuous-time active filter design, CRC Press, Boca Raton, p. 443, 1999.

[24] D. R. Frey, "Log-domain filtering: an approach to current-mode filtering," IEE Proceedings - G, vol. 140, no. 6, pp. 406-416, 1993. 


\section{Introduction}

Frequency filters are one of the basic building blocks of many analog signal processing systems. In the current technical literature, current conveyor (CC) based voltage-mode (VM) all-pass filters are widely used to correct the phase shifts caused by analog filtering operations without changing the amplitude of the applied signal $[1,2,3,4,5,6,7]$. Other types of active circuits such as quadrature or four-phase oscillators are also realized by using all-pass filters $[2,3]$. Only circuits in $[4,5]$ provide non-inverting and inverting outputs of VM all-pass filter at the same configuration. Moreover, neither of these circuits, presented in $[1,2,3,4,5,6,7]$, employ only single capacitor and active element.

In the last decade, research has also been focused on voltage conveyors (VCs). The VCs have been defined using the duality principle in 1982 [8]. As in the theory of CCs, also here the first- and second-generation VCs (VCI, VCII, IVCI, and IVCII) were described [8,9]. The best known VC is the plus-type of differential current voltage conveyor (DCVC+) [10] that is more often labelled as the current differencing buffered amplifier (CDBA) [11]. Based on the idea of the "universal" active element [12], and also on the basis of the universal current conveyor (UCC) $[13,14,15]$, the universal voltage conveyor (UVC) $[9,16,17]$ was designed and developed, using the CMOS $0.35 \mu \mathrm{m}$ technology, under the designation UVC-N1C 0520 at our workplace, and produced in cooperation with AMI Semiconductor Czech, Ltd., (now ON Semiconductor Czech Republic, Ltd.). The UVC is defined as a six-port active element, which has one voltage input $x$, two difference current inputs $(y+, y-)$, two mutually inverse voltage outputs $(z+, z-)$, and one auxiliary port $w$. By connecting or grounding suitable terminals of the UVC, it helps to realize all existing types of voltage conveyors such as VCI+, VCI-, VCI+/-, VCII+, VCII-, VCII+/-, VCIII+, VCIII-, VCIII+/-, inverting-types of voltage conveyors such as IVCI+, IVCI-, IVCI+/-, IVCII+, IVCII-, IVCII+/-, IVCIII+, IVCIII-, IVCIII+/-, and other types with differential input such as DCVC+ (CDBA), DCVC-, and DCVC+/-. The implementation method of voltage conveyors mentioned above can be found in [9]. By the modification of the UVC the differential-input buffered and transconductance amplifier (DBTA) $[18,19]$ has been defined.

The main purpose of this paper is to propose a new non-inverting and inverting output of VM all-pass filter at the same configuration using single UVC and operational transconductance amplifier (OTA) [20]. The UVC is ideal for non-inverting and inverting output of VM all-pass filter realization because of its mutually inverse voltage outputs. The phase responses of the proposed filter can be electronically shifted by the bias current of OTA. The critical component matching conditions are not required in the design. The theoretical results are verified by PSPICE simulations.

\section{Circuit description}

Using standard notation, the relationships between port currents and voltages 
of a six-port UVC are following [9]:

$$
i_{x}=i_{y+}-i_{y-}, v_{y+}=v_{w}, v_{y-}=v_{w}, v_{z+}=v_{x}, v_{z-}=v_{x}, i_{w}=0 .
$$

The OTA is a differential voltage-controlled current source with transconductance gain $g_{\mathrm{m}}$, which can be characterized by the port relations as follows [20]:

$$
I_{o}=g_{m}\left(V^{+}-V^{-}\right) .
$$

The transconductance $g_{\mathrm{m}}$ can be defined as [21]:

$$
g_{\mathrm{m}}=\frac{I_{\mathrm{B} 1}}{2 V_{\mathrm{T}}}
$$

where $V_{\mathrm{T}}$ is the thermal voltage (approximately $26 \mathrm{mV}$ at $27^{\circ} \mathrm{C}$ ) and $I_{\mathrm{B} 1}$ is the bias current to adjust the transconductance $g_{\mathrm{m}}$ of the OTA, respectively.

The proposed non-inverting and inverting output of VM first-order allpass filter, as shown in Fig. 1, employs one UVC, OTA and capacitor. Since no admittance is connected to the $x$-port, the behavior of the UVC is similar to the conventional current-feedback operational amplifier (CFOA) [22]. Note that in the proposed filter structure the OTA represents floating resistor [23]. Routine analysis yields to voltage transfer functions that can be expressed in following forms:

$$
\begin{aligned}
& T_{1}(s)=\frac{V_{o 1}}{V_{i n}}=\frac{s C-g_{\mathrm{m}}}{s C+g_{\mathrm{m}}}, \\
& T_{2}(s)=\frac{V_{o 2}}{V_{i n}}=-\frac{s C-g_{\mathrm{m}}}{s C+g_{\mathrm{m}}} .
\end{aligned}
$$

As it is seen from these equations, both non-inverting (4) and inverting (5) output of VM first-order all-pass filter can be realized with the same circuit topology.

The phase responses of the filter are given as follows:

$$
\varphi_{1}(\omega)=180^{\circ}-2 \operatorname{arctg}\left(\omega \frac{C}{g_{\mathrm{m}}}\right)=180^{\circ}-2 \operatorname{arctg}\left(\omega \frac{2 V_{\mathrm{T}} C}{I_{\mathrm{B} 1}}\right),
$$

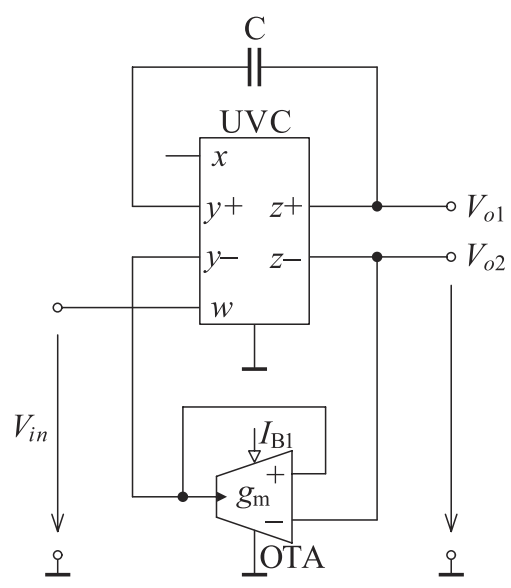

Fig. 1. Proposed non-inverting and inverting output of voltage-mode all-pass filter. 


$$
\varphi_{2}(\omega)=-2 \operatorname{arctg}\left(\omega \frac{C}{g_{\mathrm{m}}}\right)=-2 \operatorname{arctg}\left(\omega \frac{2 V_{\mathrm{T}} C}{I_{\mathrm{B} 1}}\right) .
$$

The natural frequency $\omega_{0}$ can be found as:

$$
\omega_{0}=\frac{g_{\mathrm{m}}}{C}=\frac{I_{\mathrm{B} 1}}{2 V_{\mathrm{T}} C} .
$$

As it is seen from above equations, the proposed configuration can provide phase shifting both between $180^{\circ}$ to $0^{\circ}$ and $0^{\circ}$ to $-180^{\circ}$. The shifted phase value can be controlled by bias current $I_{\mathrm{B} 1}$ of the OTA.

\section{Non-idealities and sensitivity analysis}

Taking into account the non-idealities of UVC, the relationships of the terminal voltages and currents (1) can be rewritten as:

$i_{x}=\alpha_{1} i_{y+}-\alpha_{2} i_{y-}, v_{y+}=\delta_{1} v_{w}, v_{y-}=\delta_{2} v_{w}, v_{z+}=\gamma_{1} v_{x}, v_{z-}=\gamma_{2} v_{x}, i_{w}=0$

where $\alpha_{j}=1-\varepsilon_{i j}, \delta_{j}=1-\varepsilon_{v 1 j}, \gamma_{j}=1-\varepsilon_{v 2 j}$ for $j=1,2$. Here, $\varepsilon_{i j}\left(\left|\varepsilon_{i j}\right| \ll 1\right)$ denote current tracking errors and $\varepsilon_{v 1 j}, \varepsilon_{v 2 j}\left(\left|\varepsilon_{v 1 j}\right|,\left|\varepsilon_{v 2 j}\right| \ll 1\right)$ denote voltage tracking errors of UVC, respectively. The proposed all-pass filter transfer functions (4) and (5) become:

$$
\begin{gathered}
T_{1}(s)=\frac{V_{o 1}}{V_{i n}}=\frac{\alpha_{1} \gamma_{1} \delta_{1} s C-\gamma_{1} \alpha_{2} \delta_{2} g_{\mathrm{m}}}{\alpha_{1} \gamma_{1} s C+\alpha_{2} \gamma_{2} g_{\mathrm{m}}}, \\
T_{2}(s)=\frac{V_{o 2}}{V_{\text {in }}}=-\frac{\alpha_{1} \delta_{1} \gamma_{2} s C-\alpha_{2} \gamma_{2} \delta_{2} g_{\mathrm{m}}}{\alpha_{1} \gamma_{1} s C+\alpha_{2} \gamma_{2} g_{\mathrm{m}}} .
\end{gathered}
$$

The natural frequency $\omega_{0}(8)$ can be expressed as:

$$
\omega_{0}=\frac{\alpha_{2} \gamma_{2} g_{\mathrm{m}}}{\alpha_{1} \gamma_{1} C}
$$

The active and passive sensitivities of $\omega_{0}$ are given as:

$$
S_{\alpha_{2}}^{\omega_{0}}=S_{\gamma_{2}}^{\omega_{0}}=S_{g_{\mathrm{m}}}^{\omega_{0}}=-S_{\alpha_{1}}^{\omega_{0}}=-S_{\gamma_{1}}^{\omega_{0}}=-S_{C}^{\omega_{0}}=1, S_{\delta_{1}}^{\omega_{0}}=S_{\delta_{2}}^{\omega_{0}}=0 .
$$

From Eq. (13) it is evident that the sensitivities of active and passive components for natural frequency $\omega_{0}$ are unity in relative amplitude.

\section{Simulation results}

To verify the theoretical study, the behavior of the proposed VM phase shifter has been verified by PSPICE simulations. In the simulation BJT implementations of the UVC [16] and of the OTA [21], with $\pm 2 \mathrm{~V}$ supply voltages, have been chosen. For this purpose the AT\&T bipolar transistor arrays ALA400 modeled by NR100N (NPN) and PR100N (PNP), those parameters can by found in [24], were used. The bias current $I_{\mathrm{B}}$ of the UVC has been chosen as $400 \mu \mathrm{A}$. The transconductance $g_{\mathrm{m}}$ of OTA has been set by bias current $I_{\mathrm{B} 1}$ as $22.3 \mu \mathrm{A}\left(g_{\mathrm{m}}=0.429 \mathrm{mS}\right)$ and the capacitor $C$ has been chosen as $C=68 \mathrm{pF}$. In this case a $90^{\circ}$ phase shift is at $f_{0} \cong 1 \mathrm{MHz}$. The magnitude and phase characteristics of the simulated non-inverting and inverting output of VM 


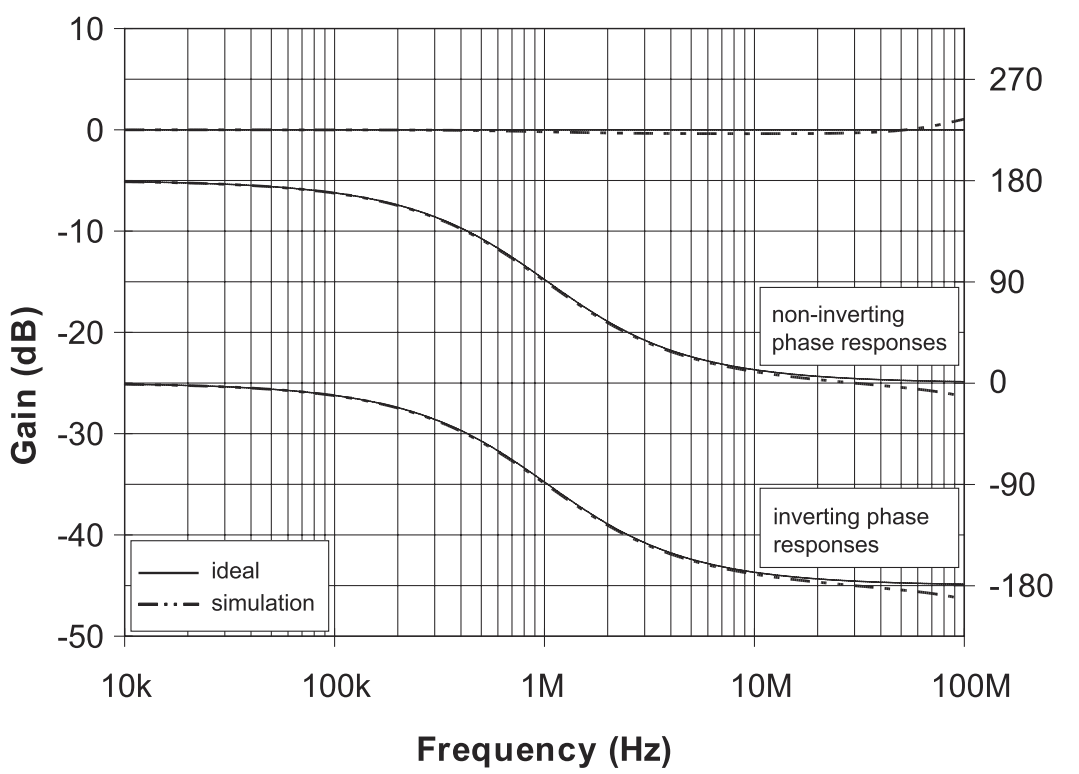

a)

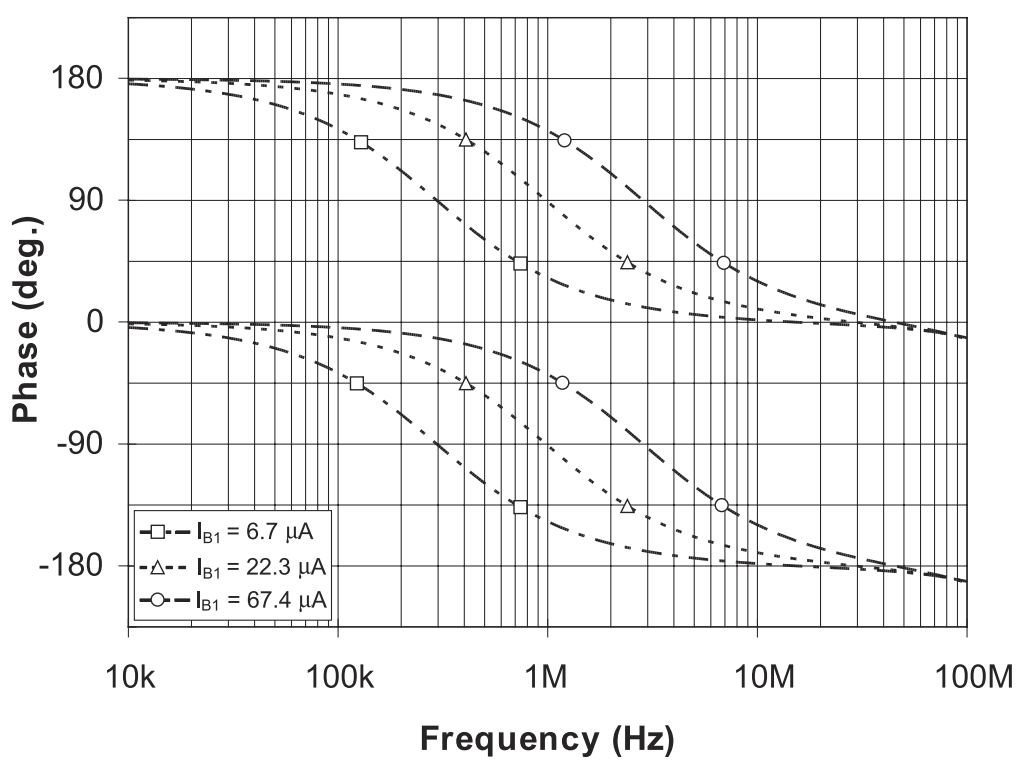

b)

Fig. 2. (a) Simulated magnitude and phase characteristics of the proposed non-inverting and inverting VM first-order all-pass filter, (b) electronical tunability of phase responses by the bias current $I_{\mathrm{B} 1}$.

first-order all-pass filter are shown in Fig. $2(\mathrm{a})$. Electronical tunability of the proposed filter for different bias current values $I_{\mathrm{B} 1}$ and corresponding phase responses are shown in Fig. $2(\mathrm{~b})$. For required values $f_{0}=\{0.3 ; 1$; $3\} \mathrm{MHz}$ the bias current $I_{\mathrm{B} 1}$ must be $I_{\mathrm{B} 1}=\{6.7 ; 22.3 ; 67.4\} \mu \mathrm{A}\left(g_{\mathrm{m}}=\{0.129\right.$; $0.429 ; 1.296\} \mathrm{mS})$. The possibility of tuning the natural frequency $f_{0}$ by the bias current $I_{\mathrm{B} 1}$ is shown in Fig. 3 .

From the simulation results it can be seen that the magnitude and phase characteristics of the proposed non-inverting and inverting VM first-order all-pass phase shifter are in good agreement with theory. 


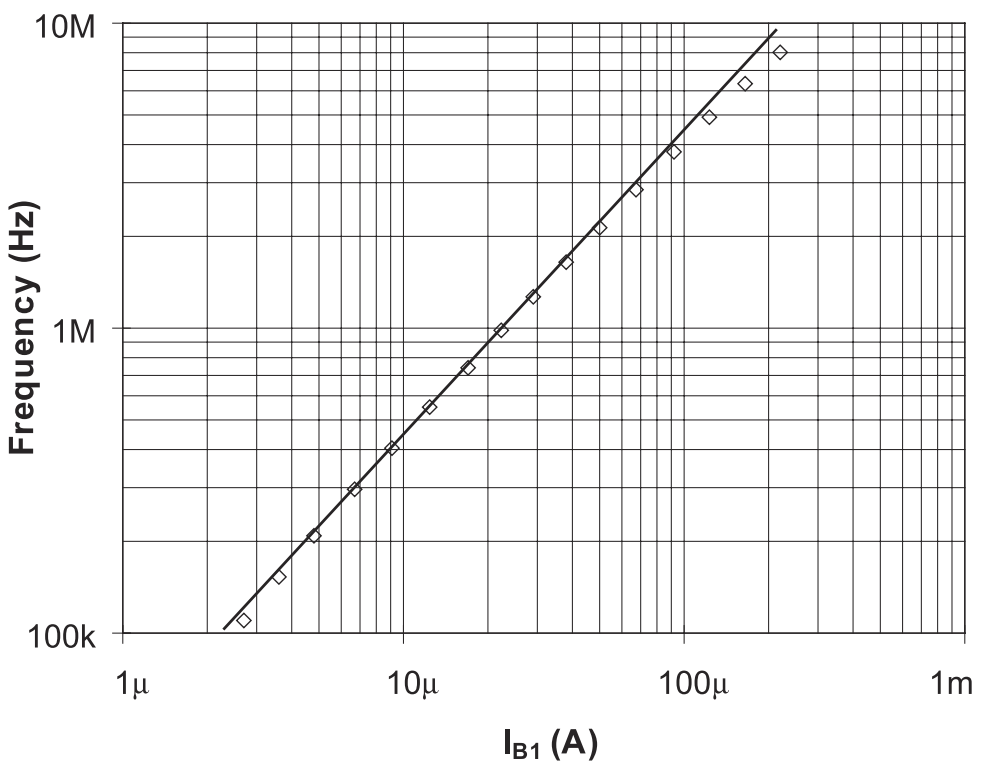

Fig. 3. Possibility of tuning the natural frequency $f_{0}$ by the bias current $I_{\mathrm{B} 1}$.

\section{Conclusion}

The paper presents new voltage-mode active-C first-order all-pass phase shifter that can provide phase shifting both between $180^{\circ}$ to $0^{\circ}$ and $0^{\circ}$ to $-180^{\circ}$. The shifted phase value can be electronically tuned with external bias current of the OTA. The proposed circuit has no requirements for component matching conditions. All the active and passive sensitivities are low. PSPICE simulation results are in good agreement with the theoretical analysis and support the feasibility of the proposed circuit.

\section{Acknowledgments}

The paper has been supported by the Czech Science Foundation project GACR 102/09/1681 and Ministry of Education of the Czech Republic project No. MSM0021630513. 